\title{
BRAINSTEM ACETYLCHOLINE SENSITIVE NEURONS ACTIVATED BY CUTANEOUS IMPULSES IN CATS
}

\author{
Nobuyoshi IWATA and Yutaka SAKAI* \\ Central Research Laboratories, Sankyo Co., Shinagawa-ku, Tokyo 140 and \\ *Department of Pharmacology, National Defence Medical College, \\ Tokorozana, Saitama 359, Japan
}

Accepted December 14, 1977

\begin{abstract}
Jn order to detcrmine the cholinoceptive mechanism associated with cutaneous inhibition of jaw-closing and lumbar motoneurons, the area related to the inhibition produced by stimulation of the superficial radial nerve was identified by a lesion within the pontomedullary reticular formation and effects of drugs upon neurons werc studied within this area. The cutaneous inhibition, as tested by the inhibition of monosynaptic reflex activity of jaw-closing and that of hindlimb spinal motoneurons was completely abolished by lesion of the medial portion of the pontomedullary reticular formation, but was little affected by lesions of the lateral portion. Intravenously administered physostigmine $(0.15-0.30 \mathrm{mg} / \mathrm{kg}$ ) excited 11 of 21 neurons whercas elcetrophoretic ACh (90 nA) excited 26 and inhibited 4 of 96 brainstem neurons located in this area. Eight of 11 physostigmine, and 4 of $26 \mathrm{ACh}$ excited neurons were reticulospinal neurons with axonal conduction velocities of $20-40 \mathrm{~m} / \mathrm{sec}$. From results presented here together with those reported previously, these physostigmine sensitive and $\mathrm{ACh}$ excited brainstem neurons, reticulospinal and non-reticulospinal neurons, could be cholinoceptive interneurons of the polysynaptic inhibitory pathway, from the superficial radial nerve to jaw-closing and hindlimb spinal motoneurons.
\end{abstract}

A muscarinic cholinergic mechanism has been suggested to be involved in the postsynaptic inhibition of jaw-closing motoneurons of the trigeminal nucleus (1) and of hindlimb spinal motoneurons (2) by forearm cutaneous impulses (cutaneous inhibition). Previous observations following lesioning indicated that the pontomedullary reticular formation was essential for the inhibition, not only of the jaw-closing but also hindlimb spinal motoneurons produced by stimulation of the superficial radial (SR) nerve $(2,3)$. It has been reported that spontaneously active, acetylcholine ( $\mathrm{ACh}$ ) sensitive neurons are located in the pontomedullary reticular formation (4-8) and also that cutaneously excited neurons are found in this area (9). All these data suggest that ACh sensitive neurons in the brainstem are involved in the polysynaptic inhibitory circuitry of the cutaneous inhibitions. In the present experiments, a study was made of the effects of intravenously administered physostigmine and electrophoretically administered $\mathrm{ACh}$ on neurons responsive to cutaneous impulses in this area. The objective was to demonstrate the possibility that ACh functions as a transmitter in the pathway of cutaneous inhibitions of these motoneurons.

\section{MATERIALS AND METHODS}

The experiments were performed on 53 adult cats which were either unanesthetized, after precollicular decerebration during ether anesthesia, or anesthetized with pentobarbi- 
tone sodium (35 $\mathrm{mg} / \mathrm{kg}$, i.p. initially, additional doses when required). Effects of lesions of the pontomedullary reticular formation on the cutaneous inhibition of the hindlimb spinal motoneurons were studied only in decerebrate and cerebellectomized animals. After all surgical operations were completed, gallamine triethiodide was administered and the animals artificially respired $(30-40 / \mathrm{min})$. The body was warmed by a pad placed under the animal and the rectal temperature was maintained around $38^{\circ} \mathrm{C}$. The blood pressure was monitored continuously from the left femoral artery.

Two pairs of collar type electrodes were implanted bilaterally on the SR nerves. The distal pair was tied to the crushed portion of the nerves. A pair of silver wire electrodes was used for stimulation of the spinal cord. The ventral side of the spinal cord between $C_{2}$ and $C_{3}$ was exposed, and a silver wire electrode (cathode) was inserted into the spinal cord near the midline. The other silver wire electrode (anode) was positioned so as to be along the entire lateral aspect of the spinal cord. These electrodes were fixed on the vertebral column with dental cement. Duration of stimulation pulse was $0.1 \mathrm{msec}$.

Monosynaptic reflexes (MSRs) were recorded from the masseter nerve following stimulation of the mesencephalic trigeminal tract (MTT), as described in detail in a previous paper (1). The spinal MSR was recorded from the $L_{7}$ ventral root following stimulation of the medial gastrocnennius-soleus $(\mathrm{mG}-\mathrm{S})$ nerve, as described in detail in a previous paper (2).

When a lesion was made in the brainstem, care was taken by using fine scissors and a number of small lesions was made in order to avoid as much as possible abrupt blood pressure changes. The blood pressure did, however, increase during and immediately after the lesioning. In this phase, the amplitude of the MSR fluctuated. Gradually over a 15-30 min period, the blood pressure recovered and remained constant. The MSR also maintained a consistent amplitude. Therefore, effects of lesioning of the brainstem on the cutaneous inhibitions were always studied after the blood pressure and amplitude of the MSRs had recovered to normal level and remained constant.

In a series of experiments to determine the effects of intravenously administered physostigmine on the brainstem neurons, a glass recording microelectrode filled with $1 \mathrm{M} \mathrm{K}$-acetate saturated with methylblue (resistance approximately $10 \mathrm{M} \Omega$ ) was inserted into the brainstem by a pharyngeal approach through a hole made in the basioccipital bone of the supinepositioned animal (10). Potentials recorded from the masseter nerve, $L_{7}$ ventral root, and through the microelectrode were amplified, displayed on a cathode-ray oscilloscope and photographed.

Reticulospinal neurons (RS) were identified by antidromic stimulation of their axons in the spinal cord. Three criteria have been described by Wolstencroft (11) to distinguish antidromic excitation of RS neurons and two were used in this study. The first was a response with short and constant latency following stimulation of the spinal cord. The second was the ability of a neuron to respond to each stimulus at rates of $100-300 \mathrm{~Hz}$.

Physostigmine salicylate and atropine sulphate were dissolved in physiological saline at 0.1 and $1 \%$ concentrations, respectively and were administered i.v. into the femoral vein 
relatively slowly so as to avoid abrupt fall in blood pressure.

The average number of SR-evoked spike discharges or frequency of spontaneous firing rates of the brainstem neurons were calculated from 5 traces superimposed immediately before and at an appropriate time after the drug administration.

In a series of experiments to study effects of $\mathrm{ACh}$ on brainstem neurons, a double barrel electrode was used. A pair of glass micropipettes was mounted on a small manipulator (HMD-2, Narishige). One, filled with $1 \mathrm{M} \mathrm{K}$-acetate saturated with methylblue was used for recording (resistance approximately $10 \mathrm{M} \Omega$ ). The other (tip diameter, $1-3 / / \mathrm{m}$ ) was used to administer ACh electrophoretically, and was filled with $1.0 \mathrm{M} \mathrm{ACh}$ chloride dissolved in distilled water $(\mathrm{pH}, 3.0)$. These two micropipettes were fixed to each other with acryl resin (Aron Alpha, Sankyo) and dental cement while viewed under a microscope in order to set the gap between the tips at 30-50, was administered to all neurons in response to stimulation of the SR nerve of either side by passing DC current or long duration pulses of $300 \mathrm{msec}$ at $1 \mathrm{~Hz}$ for $20-90 \mathrm{sec}$ through the pipette.

In order to obtain a constant current for iontophoretic application of $\mathrm{ACh}$, a $1000 \mathrm{M} \Omega$ resistor was connected in a series between the positive pole of a battery ( $90 \mathrm{~V}$ ) and the ACh containing electrode.

The average number of SR-evoked spike discharges or frequency of spontaneous firing rates of the brainstem neurons and their standard errors (S.E.) was calculated from successive 5 traces before, during and after administration of ACh. Significant increase in their number of spikes or spontaneous firing rate of the neurons after drug administration was determined statistically ( $t$-test). When the number of discharges of the brainstem neurons was increased by physostigmine (systemically) or $\mathrm{ACh}, \mathrm{DC}$ current $(10 \mu \mathrm{A})$ was passed through the recording electrode for $5 \mathrm{~min}$ to release methylblue. All animals were sacrificed immediately after each experiment and the brain was removed for histological examination.

\section{RESULTS}

Results will be presented in three sections. First, effects of localized lesions of the pontomedullary reticular formation upon the cutaneous inhibition of jaw-closing and hindlimb spinal motoneurons, secondly, effects of intravenously administered physostigmine on spike activity evoked from the SR nerve, and finally effects of electrophoretic ACh on these activities.

1. Effects of localized lesions in the pontomedulary reticular formation on the cutaneous inhibition of jaw-closing and hindlimb spinal motoneurons

To determine rough structures involved in the inhibitory pathways from the SR nerve to either jaw-closing or hindlimb spinal motoneurons, localized lesions were made in the pontomedullary reticular formation and the cutaneous inhibition, as seen in the magnitude of the MSR, was compared before and after the lesions.

On jaw-closing motoneurons: Lesions were made in 5 cats and the results of two examples are illustrated in Figs. 1,2. As already reported (1), the MTT was stimulated twice at 
an interval of approximately $1.5-3.0 \mathrm{msec}$ to evoke the masseteric MSR in cats anesthetized with pentobarbitone sodium (Fig. 1A and Fig. 2A). As shown in Fig. 1B and C, the MSR in this preparation was suppressed about $45 \%$ by preceding stimulation of either ipsilateral (B) or contralateral (C) SR nerve at an interval of $7 \mathrm{msec}$. This inhibition is known to be accompanied by inhibitory postsynaptic potentials (IPSPs) recorded from jaw-closing motoneurons $(1,3,12)$. After cutting the lateral portion of the potomedullary reticular formation with fine scissors, as shown in Fig. 1S, the MSR was not altered (D), and the cutaneous inhibition of the masseteric MSR was reduced fron $45 \%$ to $35 \%(\mathrm{E}, \mathrm{F})$. Extension of the lesion to the medial portion of the reticular formation (T) almost completely abolished this cutaneous inhibition of the MSR ( $\mathrm{H}, \mathrm{I})$ without influencing the MSR (G).

In another cat, effects of smaller lesions of the medial portion of the reticular formation

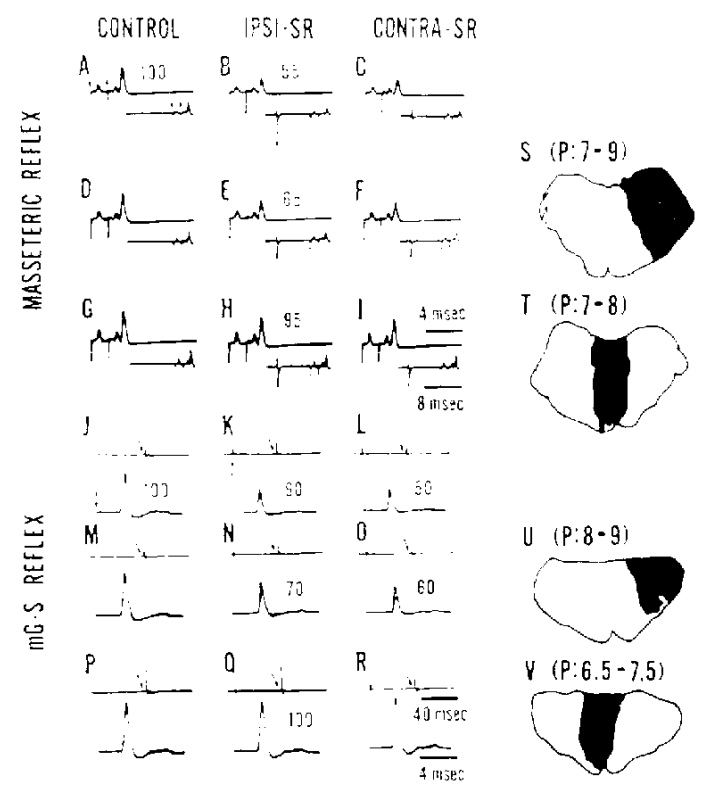

FIG. 1. Effects of small lesions of the pontomedullary reticular formation on cutaneous inhibitions of jaw-closing and hindlimb spinal motoneurons in the cat. A, D, G: masseteric monosynaptic reflex (MSR) evoked by double shock stimulation of the mesencephalic trigeminal tract (MTT). B, E, H and C, F, I: inhibition of the masseteric MSR by conditioning stimulation of the ipsilateral $(B, E, H)$ and contralateral $(C, F, 1)$ superficial radial (SR) nerve at an interval of approximately 5 msec. J, M, P: spinal MSR croked by medial gastrocnemius-soleus (mG-S) nerve stimulation. $\mathrm{K}, \mathrm{N}, \mathrm{Q}$ and $\mathrm{L}, \mathrm{O}, \mathrm{R}$ : inhibition by conditioning stimulation of the ipsilateral $(K, N, Q)$ and contralateral $(L, O, N)$ SR nerve at an interval of approximately $50 \mathrm{msec}$. Upper traces in A-I and lower traces in $\mathrm{J}-\mathrm{R}$ : oscilloscopic trace was triggered by the first shock stimulus to the MTT. A-C and J-L: intact pontomedullary reticular formation; D-F and M-O: after lesion of the lateral portion of the pontomedullary reticular formation as indicated in $\mathrm{S}$ and $\mathrm{U}$, respectively; G-I and P-R: after section of the medial portion of the pontomedullary: reticular formation as illustrated in $T$ and $V$, respectively. Numbers in each trace indicate the percent amplitude of test MSR when the control value is represented by $100 \%$ Calibrations: as indicated. Numbers in parentheses indicate the level of the brain atlas from AP-O. 


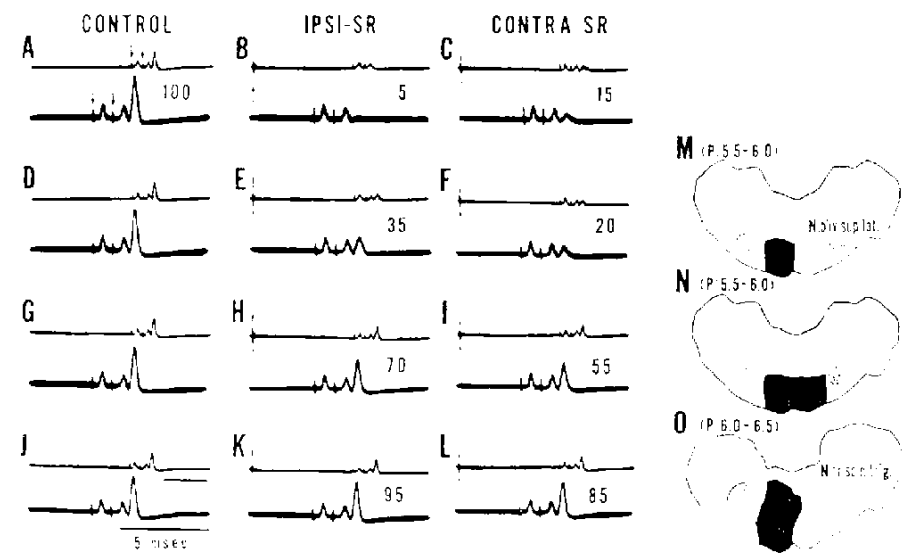

Fic. 2. Efiects of localized lesions of medial portion of the pontomedullary reticular formation on cutaneous inhibition of the jaw-closing motoncurons. $A, D, G, J$ : masseteric MSR, B, E, H and C, F, I, L: inhibition of the masseteric MSR by conditioning stimulation of the ipsilateral $(B, E, H, K$ ) and contralateral $(C, F, I$, L) SR nerve at an interval of approx $10 \mathrm{msec}$. Lower traces in A-L: masseteric MSR are indicated by expanded sweep speed. A-C: intact pontomedullary reticular formation, D-F : after small lesioning of the ipsilateral medial portion of the pontomedullary reticular formation as indicated in M. G-I: after addition of a small lesion of the contralateral reticular formation as illustrated in N. J-L : after addition of large lesion of the ipsilateral reticular formation as demonstrated in $O$. Numbers in each trace indicate amplitude of testing MSR when the control value of each scries (A-C, D-F, G-I, J-L) is I00. Calibrations: as indicated.

were studied on this cutaneous inhibition. As illustrated in Fig. 2, the MSR in this preparation was suppressed by conditioning stimulation of the ipsilateral $(95 \%$, B) and contralateral $(85 \%$ C) SR nerve at an interval of $10 \mathrm{msec}$. In the case of small lesions of the ipsilateral reticular formation (M), the cutaneous inhibition was slightly suppressed to $65(\mathrm{E})$ and 80 (F) percent. After a small lesion was made in the contralateral reticular formation (N), the cutaneous inhibition was remarkably depressed to about $30(\mathrm{H})$ and 45 (I) percent. Extension of lesion to the dorsal portion of the ipsilateral reticular formation $(\mathrm{O})$ almost completely abolished the cutaneous inhibition (K, L). To eliminate the cutaneous inhibition completely, a sinilar lesion had to be made in the contralateral reticular formation.

These results indicate firstly that the medial, and not lateral, portion of the pontomedullary reticular formation is essential for cutaneous inhibition of jaw-closing motoneurons. Secondly, unilateral section of the medial reticular formation reduced the cutaneous inhibition produced by stimulation of either the ipsilateral or contralateral SR nerve and lastly almost the entire medial portion, and not particularly dorsal or ventral areas, of the reticular formation is required for cutaneous inhibition.

Hindimb spinal motoneurons: Lesions were made in 5 decerebrate and cerebellectomized cats. One example is illustrated in Fig. 1. As shown in this figure (lower half), the spinal MSR evoked by stimulation of the $\mathrm{mG}-\mathrm{S}$ nerve ( $\mathrm{J}$ ) was suppressed by conditioning stimulation of the ipsilateral (by about $40 \%$ K) or contralateral (about $50 \%$, L) SR nerve stimulation at an interval of approximate $50 \mathrm{msec}$. The time course of this inhibition has been 
described elsewhere $(2,3)$. Sectioning of the lateral portion of the pontomedullary reticular formation (C) did not affect the amplitude of the MSR (M) and only slightly reduced the cutaneous inhibition of the hindlimb spinal MSR $(N, O)$. The inhibition was completely abolished $(\mathrm{Q}, \mathrm{R})$, however, after sectioning the medial portion (V) of this region without a concomitant change in the control MSR size (P).

From the results of these experiments, it is apparent that the medial reticular formation is necessary for the cutaneous inhibition of jaw-closing motoncurons, as well as of hindlimb spinal motoneurons. These findings confirm and extend previous observations that an integrity of the pontomedullary reticular formation is necessary for cutaneous inhibition (3).

2. Effects of intravenously administered physostigmine on brainstem neurons activated by the $S R$ nerve

Since the medial portion of the pontomedullary reticular formation appears to be essential for the cutaneous inhibition, it was assumed that interneurons for the cutaneous inhibition may be located within this region. A search was thus made for neurons responding to physostigmine and/or ACh which were activated from the SR nerve and had axons descending to the spinal cord (RS neurons).

As is already known $(9,11)$, a single pulse stimulation of the SR nerve excites brainstem neurons. About $80 \%$ of brainstem neurons tested discharged repetitively in response to a single stimulus at a supramaximal intensity for $A_{\alpha}$ afferent fibers. As illustrated in Fig. $3 \mathrm{~A}$, the latency of the first action potential ranged from $4.5 \mathrm{msec}$ to $18 \mathrm{msec}$ following stimulation of the SR nerve. Of 21 such brainstem neurons, 15 were identified as RS neurons with antidromic latencies ranging from 0.5 to $1.8 \mathrm{msec}$ (Fig. 3B).

One example of effects of physostigmine on these brainstem neurons (15 RS and 6 non-RS neurons) is illustrated in Fig. 4. The antidromic action potential of the RS neuron had a constant latency of $1.8 \mathrm{msec}$ following stimulation of the spinal cord at $\mathrm{C}_{2-3}$, and
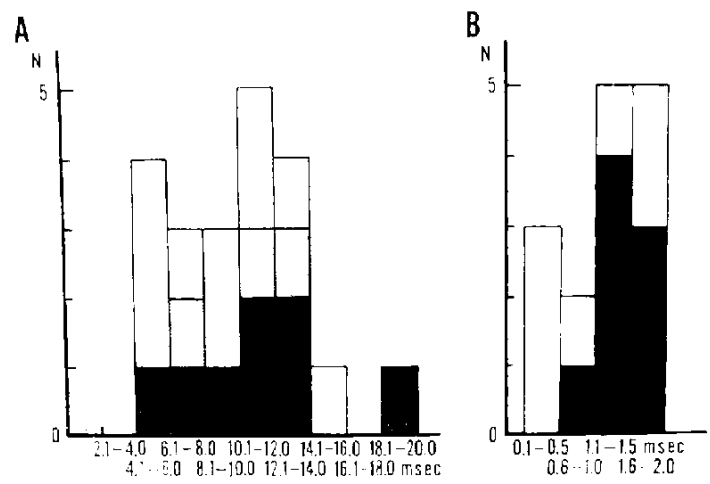

FIG. 3. Latency histogram of physostigmine-sensitive brainstem neurons responsive to cutaneous impulses. Ordinates: number of neurons. Abscissa: latency of the initial discharge evoked by stimulation of either SR nerve (A) and the antidromic latency of RS neurons following stimulation of $\mathrm{C}_{2-3}$ spinal segments (B). Black column, RS neurons excited by physostigmine; dotted column, excited non-RS neurons; white column, neurons unaffected by physostigmine. 
firing followed stimulation at $100 \mathrm{~Hz}$. This neuron responded with an orthodromic latency of $7 \mathrm{msec}$ following stimulation of the SR nerve, and the discharges lasted for about $30 \mathrm{msec}$ (Fig. 4A). On the average, each stimulus produced 4.8 spikes. This neuron also fired spontaneously at a mean frequency of $12 \mathrm{~Hz}$ as shown in Fig. 4D. Physostigmine was given (i.v.) twice at intervals of $10 \mathrm{~min}$. The first injection of physostigmine $(0.15 \mathrm{mg} / \mathrm{kg})$ increased the number of SR-evoked action potentials slightly and the number of discharges increased $5 \mathrm{~min}$ after the second injection of the same dose of physostigmine (Fig. 4B, G). The spontaneous firing rate also increased to a maximum of about $24 \mathrm{~Hz}$ (Fig. 4E, G).

Since it is impossible to discriminate the SR-evoked spikes from spontaneous firing ones, the latter was counted in the former. However, in $100 \mathrm{msec}$ of sweep time before the drug administration, the average numbers of SR-evoked spikes (involving spontaneous firing ones, Fig. 4A) and spontancously firing spikes alone (Fig. 4D) were 4.8 and 1.2, respectively. Therefore, in control, pure SR-evoked spikes can be estimated as 3.6 in number by subtracting the latter from the former. At $5 \mathrm{~min}$ after the second administration of physos-

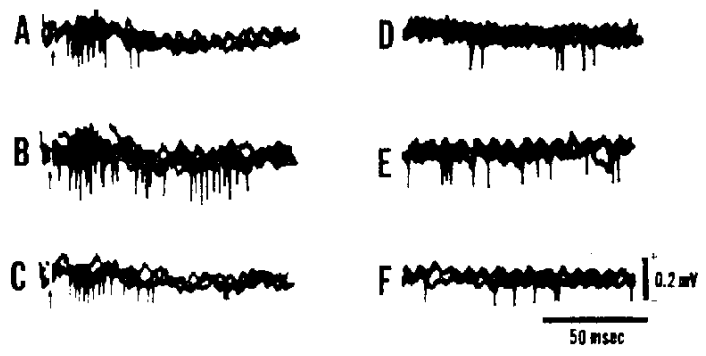

G

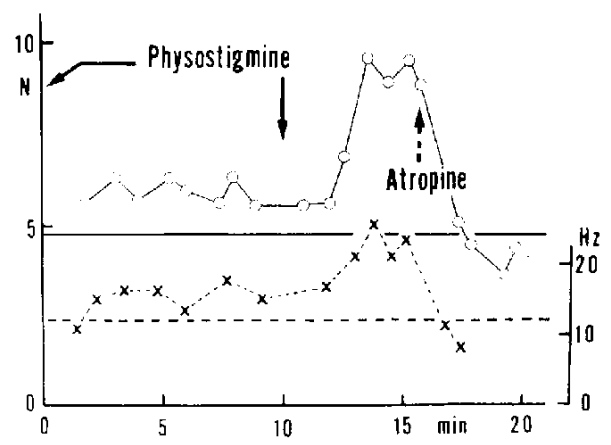

FjG. 4. Effects of physostigmine on a reticulospinal (RS) neuron activated by SR nerve stimulation. A-C: cutaneously evoked repetitive discharges, D-F: spontaneous firing. A, D: control; B, E: 5 min after the second injection of physostigmine; C, F: 3 min after atropine $(1 \mathrm{mg} / \mathrm{kg}$, i.v.). Five traces were super-imposed in A-F. G: time course of physostigmine effect and antagonism by atropine. Circles and left ordinate: number of cutancously evoked discharges, crosses and right ordinate: spontaneous firing frequency. Abscissa: time after the first administration of physostigmine. Horizontal straight and dotted line: average number of SR-evoked spikes and average frequency of spontaneously firing spikes, respectively in control. Calibrations: as indicated. 
tigmine, the number of SR-evoked spike discharges including spontaneously firing ones (Fig. 4B, G) was 9.6 and the number of spontaneously firing spikes alone (Fig. 4E) was 2.4. This suggests that the number of pure SR-evoked spike discharges is approximately 7.2. Hence physostigmine apparently increases not only the rate of spontaneously firing spikes but SR-evoked spike discharges in brainstem neurons. These changes in discharge rate were reversible and the rate returned to the control level within 3 min after the administration of atropine ( $1 \mathrm{mg} / \mathrm{kg}$, i.v., Fig. 4C, F). This antagonism by atropine was confirmed with 4 RS neurons. The time course of physostigmine effect and antagonism by atropine is illustrated in Fig. 4G.

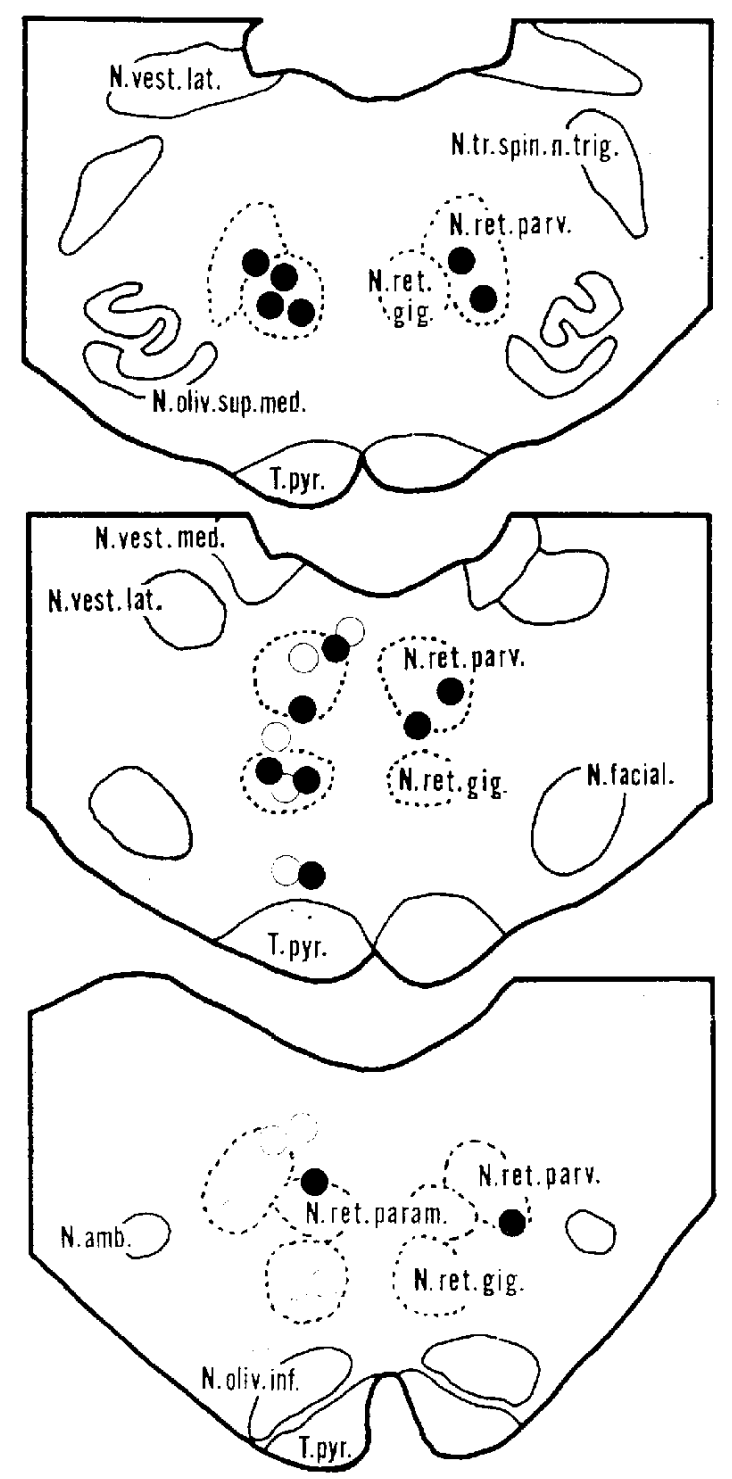

FIG. 5. Localization of brainstem neurons excited by physostigmine (open circles) and $\mathrm{ACh}$ (filled circles) responsive to SR nerve stimulation. 
As shown in the solid and shaded columns in Fig. 3, physostigmine $(0.15-0.30 \mathrm{mg} / \mathrm{kg})$ increased the number of spike discharges in 11 of 21 brainstem neurons and did not affect the others. Eight of eleven excited neurons were RS (black columns of Fig. 3A and B), the average latency of the initial action potentials being $10.5 \mathrm{msec}$ (range 5-20 msect after SR nerve stimulation (Fig. 3A). The average antidromic latency of these RS neurons was $1.3 \mathrm{msec}$ (range $0.9-1.8 \mathrm{msec}$, Fig. 3B).

Histological examination showed that these brainstem neurons sensitive to physostigmine were located in the nucl. reticularis gigantocellularis (3), nucl. reticularis parvocellularis (3) and formatio reticularis (5). These anatomical sites are illustrated in Fig. 5 by open circles at three different levels $(\mathrm{P}=6.5,7.5$ and 8.0 according to the atlas of Snider and Niemer (13)).

3. Effects of $A C h$ on brainstem nemrons responsive to $S R$ nerve stimulation

The effect of ACh was studied on 96 brainstem neurons, of which the rate of discharge of 26 was increased, 4 decreased while the other 66 were not affected. Of 26 neurons excited
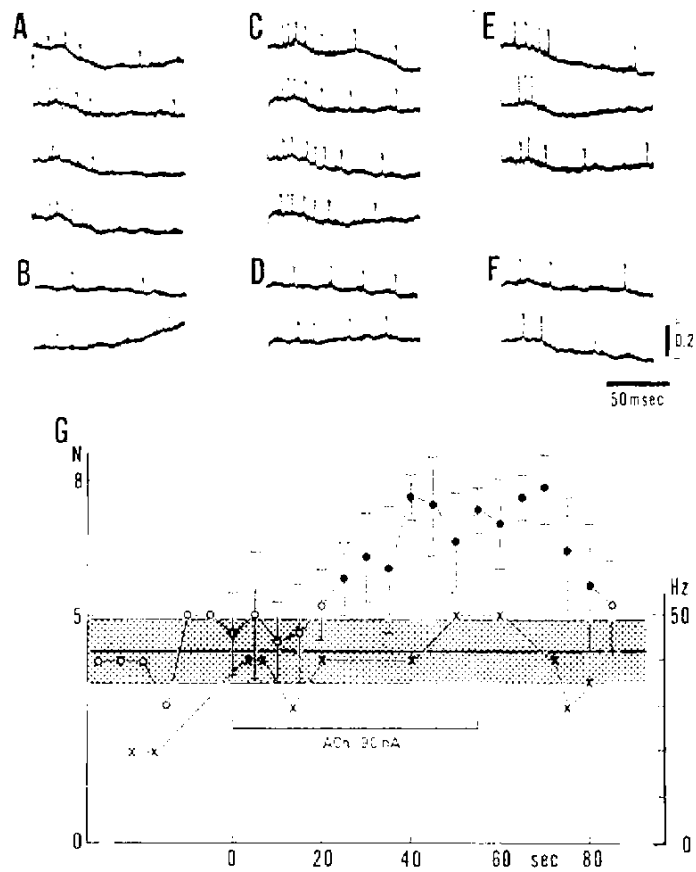

FIG. 6. Facilitatory effect of electrophoretic ACh on a brainstem non-RS ncuron responsive to SR nerve stimulation. A, C, E: cutaneously evoked discharges: $\mathrm{B}, \mathrm{D}, \mathrm{F}$ : spontaneous firing. $\mathrm{A}, \mathrm{B}$ : control: $\mathrm{C}, \mathrm{D}$ : during $\mathrm{ACh}$ ejection with $90 \mathrm{nA} ; \mathrm{E}, \mathrm{F}$ : after termination of injection. Calibrations: as indicated. G: time course of ACh effect. Horizontal heavy line and dotted area; average number of cutaneously evoked spikes and S.E. $(n=6)$, respectively in control. Circles and left ordinate: number of cutancously evoked discharges; vertical bars indicate S.E. $(n=5)$, filled circles indicate values significantly different from those which are unfilled $(\mathrm{P}<0.05)$; crosses and right ordinate: spontaneous firing frequencs: Abscissa: time (sec). 
by $\mathrm{ACh}, 14$ were tested by high frequency stimulation of the spinal cord and only 4 were identified as RS neurons. This test was not carried out with the other 12. The antidromic latencies of these RS neurons were 1.0 ( 1 neuron), 1.2 ( 2 neurons) and $1.4 \mathrm{msec}$ ( 1 neuron) following cord stimulation. One example of the facilitatory effect of $\mathrm{ACh}$ is illustrated in Fig. 6. This neuron responded to a single stimulation of the SR nerve with $3-5$ discharges $(4.1 \pm 0.7$, mean \pm S.E., $n=6$ ) (Fig. 6A) and also fired spontaneously with a frequency of $10-20 \mathrm{~Hz}$ (Fig. 6B). The latency of the initial action potential evoked by cutaneous impulses was approximately $10 \mathrm{msec}$ and repetitive discharges lasted for about $20 \mathrm{msec}$. The number of discharges, either spontaneous or cutaneously evoked (estimated similarly as described in the former section), increased when $\mathrm{ACh}$ was ejected with a current of $90 \mathrm{nA}(\mathrm{C}, \mathrm{D})$ : the time course of the effects of ACh are illustrated in Fig. 6G. A significant increase in the number of SR-evoked discharges (filled circles, $P<0.05$ ) started at about $25 \mathrm{sec}$ and attained a maximum $40 \mathrm{sec}$ after the onset of the current used to eject $\mathrm{ACl}$. The maximum effect of ACh lasted for approximately $15 \mathrm{sec}$ after the termination of the current and then gradually decayed over the following $30 \mathrm{sec}$ (Fig. 6C, E and G).

The firing of four neurons was depressed by ACh. The latent period of the ACh effect (either facilitatory or inhibitory) differed from cell to cell, the shortest latency was $3 \mathrm{sec}$ and the longest $40 \mathrm{sec}$ after the beginning of the electrophoretic current. Most of the latencies were distributed between 10 and $20 \mathrm{sec}$, while the time for discharge rate to return to the control level after turning off the current also varied from 7 to $30 \mathrm{sec}$.

The histogram of the orthodromic latencies of $\mathrm{ACh}$ sensitive neurons is illustrated in Fis. 7. Latencies of the initial action potential of these neurons were distributed from 6.2 to $60 \mathrm{msec}$, mostly from 6.2 to $24 \mathrm{msec}$ following stimulation of the SR nerve. The duration of the repetitive discharges was $5-30 \mathrm{msec}$. There was no correlation between latency of discharges and acetylcholine sensitivity.

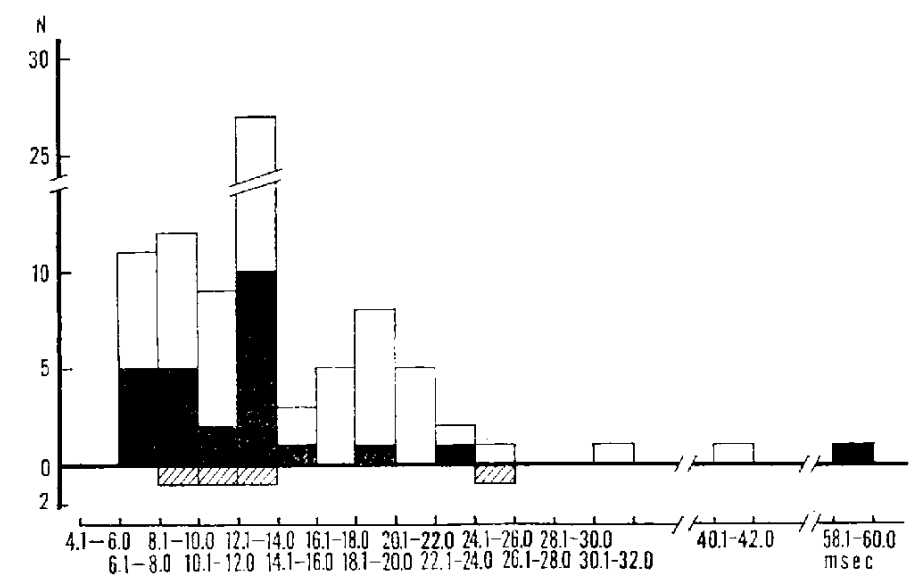

FIG, 7. Latency histogram of the ACh sensitive brainstem neurons responsive to cutaneous impulses. Ordinate: number of neurons; abscissa: orthodromic latency evoked by stimulation of either SR nerve. Black column: neurons excited by $\mathrm{ACh}$; cross-hatched column: neurons inhibited by $\mathrm{ACh}$. 
Histological examination indicated that neurons excited by $\mathrm{ACh}$ were also located, as were neurons affected by physostigmine, in the nucl. reticularis gigantocellularis (5), nucl. reticularis paramedianus (1), nucl. reticularis parvocellularis (8) and formatio reticularis (1) (Fig. 5, filled circles).

\section{DISCUSSION}

The present experiments demonstrated that the medial, not lateral, portion of the pontomedullary reticular formation is essential for the cutaneous inhibition of jaw-closing as well as hindlimb spinal motoneurons. Both of these cutaneous inhibitions were completely abolished by a complete transection of the medial reticular formation. Since a small lesion of the medial reticular formation slightly reduced the cutaneous inhibition of jaw-closing motoncurons, the inhibitory pathways, including inhibitory interneurons, from the SR nerve to the jaw-closing motoneurons may be located diffusely in the medial reticular area.

The inhibition of jaw-closing and of hindlimb spinal motoneurons evoked by impulses to $A_{i t}$ afferent fibers of the SR nerve may involve a muscarinic cholinergic mechanism (1, 2). In the present experiments intravenously administered physostigmine $(0.15-0.30 \mathrm{mg} / \mathrm{kg})$ excited 11 of 21 and electrophoretic ACh excited 26 of 96 brainstem neurons which responded to stimulation of the SR nerve of either side at a supramaximal intensity for stimulating $\mathrm{A}_{\alpha}$ afferent fibers and were located in the medial reticular area. This location is in fairly good agreement with that of $\mathrm{ACh}$ sensitive neurons determined by their spontaneous activity $(5,6)$ and with that of neurons responding to SR nerve stimulation $(9)$.

The effect of physostigmine was completely antagonized by atropine in all neurons tested. This could be relevant to a cholinergic synaptic mechanism influencing these particular neurons. Atropine antagonism, however, was tested on only 4 of 11 physostigmine sensitive neurons and as this effect of atropine was long lasting, the effect of atropine alone was not studied. According to Bradley et al., (7), electrophoretic physostigmine potentiated the action of $\mathrm{ACh}$, but in addition to this action, it had a strong excitatory effect on many brainstem neurons. Hence it may be possible that some of the physostigmine sensitive neurons upon which atropine antagonism was not tested, might have been excited by physostigmine, independent of the effects of ACh. Electrophoretic ACh, however, excited 26 of 96 brainstem neurons which were located in the medial portion of the pontomedullary reticular formation found to be essential for the cutaneous inhibitions studied, and responded to the same cutaneous impulses required to produce inhibitions of masseter and lumbar motoneurons. Eight of 11 physostignine-sensitive and 4 of 26 ACh excited neurons were RS, the average antidromic latency was $1.3 \mathrm{msec}$ (range, $0.9-1.8 \mathrm{msec}$ ) following stimulation of the $\mathrm{C}_{2-3}$ spinal segments. The calculated average conduction velocity was approximately $30 \mathrm{~m} / \mathrm{sec}$ (range, $2040 \mathrm{~m} / \mathrm{sec}$ ). According to Wolstencroft (11) conduction velocities of RS neurons were distributed between $20-138 \mathrm{~m} / \mathrm{sec}$, and hence, the RS neurons which responded to forearm cutaneous impulses and are excited by either physostigmine or ACh may fall into a group of RS neurons having slower conduction velocities. 
Sixty-six neurons were unaffected by ACh. There may have been non-cholinoceptive brainstem neurons. Alternatively the dose of iontophoretically applied ACh might be insufficient for some of the brainstem neurons to produce the response partly because of long distance between recording and ACh containing electrode and the sensitivity of cells could have been reduced by pentobarbitone sodium.

The latency of the first SR-evoked action potential of brainstem neurons sensitive to either physostigmine or ACh ranged from 6 to $60 \mathrm{msec}$, mostly from 6 to $24 \mathrm{msec}$. These values are in good agreement with those reported by others, although the effects of either physostigmine or $\mathrm{ACh}$ on these neurons were not studied $(9,11,14)$. The duration of discharges ranged between 5 and $30 \mathrm{msec}$. The latency and duration of discharges of physostigmine and/or ACh excited neurons (RS and non-RS neurons) roughly coincide with those of IPSPs recorded from jaw-closing motoneurons following stimulation of the same cutaneous nerve $(1,3,12)$. Whether or not physostigmine or ACh excited RS neurons have ascending axons was not studied, as the distance between jaw-closing motoneurons and these RS neurons is quite short. Some RS neurons, however, are known to have ascending axons $(14,15)$.

Although we did not do tests to determine whether or not IPSPs could be recorded from jaw-closing and lumbar motoneurons following stimulation of the areas where these physostigmine and/or ACh excited neurons were located, these brainstem neurons may be cholinoceptive interneurons involved in the cutaneous inhibition of jaw-closing motoneurons. Recently Nakamura et al. (16) recorded monosynaptic IPSPs from trigeminal motoneurons following stimulation of the medial bulbar reticular formation.

Although 11 of 21 physostigmine sensitive neurons were RS neurons, only 4 of $14 \mathrm{ACh}$ sensitive neurons tested were RS neurons. This suggests two possibilities; 1) ACh might not reach many RS neurons recorded, even though these neurons may be directly activated by $\mathrm{ACh}, 2$ ) RS neurons may not be directly activated by $\mathrm{ACh}$, as was discussed by Shute and Lewis who carried out histological studies (17), but may be activated indirectly by ACh sensitive non-RS neurons. Since the number of neurons involved in the present experiments was small, further study is required to determine which of these possibilities is the more likely.

Our present results are compatible with function of medial reticular cholinoceptive neurons in the inhibitory pathways studied, but further investigation is required regarding the effects of ACh antagonists such as atropine and dihydro- $\beta$-erythroidine on the synaptic excitation of these cells. The available evidence suggests that these brainstem neurons are probably cholinoceptive interneurons within the system of the cutaneous inhibition of the jaw-closing and hindlimb spinal motoneurons.

Acknowledgement: We express our gratitude to Mr. S. Aoshima for excellent technical assistance and Mrs. Y. Nomura for histological examination.

\section{REFERENCES}

1) Iwata, N., SaKaI, Y. AND Deguchi, T.: Effects of physostigmine on the inhibition of tri- 
geminal motoneurones by cutaneous impulses in the cat. Exp. Brain Res. 13, 519-532 (1971)

2) Iwata, N. and Sakal, Y.: Cholinergic mechanism in the inhibition of spinal reflexes from the superficial radial nerve of the decerebrate cat. Experientia 27, 1418-1419 (1971)

3) Kubota, K., Kidokoro, Y. and Suzuki, J.: Postsynaptic inhibition of trigeminal and lumbar motoneurones from the superficial radial nerve in the cat. Japan. J. Physiol. 18, 198$215(1968)$

4) Machne, X. and Unina, K.R.W.: Action at the central nervous system. Handbuch der Experimentellen Pharmakologie, Vol. 15, p. 679-700, Edited by KofLle, G.B., Springerverlag, Berlin, Göttingen and Heidelberg (1963)

5) Salmoiraghi, G.C. And Steiner, F.A.: Acetylcholine sensitivity of cat's medullary neurones. J. Netrophysiol. 26, 581-597 (1963)

6) Avanzino, G.L., Bradley, P.B. ANd Wolstencroft, J.H.: Pharmacological properties of neurones of the paramedian reticular nucleus. Experientia 22, 410 (1966)

7) Bradley, P.B., Dhawan, B.N. and Wolstencroft, J.H.: Pharmacological properties of cholinoceptive neurones in the medulla and pons of the cat. $J$. Physiol. 183, 658-674 (1966)

8) Tebecis, A.K.: Transmitters and reticulospinal neurones. Exp. Neurol. 40, 297-308 (1973)

9) Pompeinano, O. And Swetr, E.: Actions of graded cutaneous and muscular afferent volleys on brainstem units in the decerebrate, cerebellectomized cat. Archs ital. Biol. 101, 552-613 (1963)

10) Ito, M., Hongo, T., Yoshida, M., Okada, Y. and Obata, K.: Antidromic and trans-synaptic activation of Deiter's neurones induced from the spinal cord. Japan. J. Physiol. 14, 638-658 (1964)

11) Wolstencroft, J.H.: Reticulospinal neurones. J. Physiol. 174, 91-108 (1964)

12) Kidokoro, Y., KubOTA, K., SHUto, S. AND Sumino, R.: Reflex organization of cat masticatory muscles. J. Neurophysiol. 31, 695-708 (1968)

13) Snider, R.S. And Nifmer, W.T.: A Stereotaxic Atlas of the Cat Brain. The University of Chicago Press, Chicago (1961)

14) MaGNi, F. AND WiLLis, W.D.: Subcortical and peripheral control of brainstem reticular neurones. Archs ital. Biol. 102, 434-448 (1964)

15) ITO, M., Udo, M. AND MANo, M.: Long inhibitory and excitatory pathway converting onto cat reticular and Deiter's neurones and their relevance to reticulofugal axons. J. Neurophysiol. 33, 210-226 (1970)

16) Nakamura, Y., Takatori, M., NOZAKI, S. and KikUChi, M.: Monosynaptic reciprocal control of trigeminal motoneurone from the medial bulbar reticular formation. Brain Res. 89, 144-149 (1975)

17) Shlte, C.C. AND Lewis, P.R.: Cholinesterase-containing pathways of the hindbrain: afferent cerebellar and centrifugal cochlear fibers. Nature 205, 242-246 (1965) 